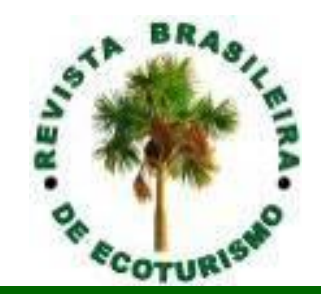

\title{
Planejamento e gestão de Unidades de Conservação: um olhar sobre a Estação Ecológica de Bananal (SP)
}

\author{
Planning and management of Protected Areas: \\ a look at the Bananal Ecological Station (SP, Brazil)
}

\author{
Alessandra Freire dos Reis, Maria Inez Pagani
}

\begin{abstract}
RESUMO: As Unidades de Conservação têm como missão salvaguardar o patrimônio natural e cultural. Para que cumpram seus objetivos é necessário dotá-las de recursos e instrumentos de planejamento e gestão. Neste trabalho, analisou-se os processos de planejamento e gestão da Estação Ecológica de Bananal (EEB), localizada na Serra da Bocaina no Estado de São Paulo. A pesquisa foi realizada desde o período da implantação do Plano de Gestão Ambiental (PGA), publicado em 1998 até a conclusão do seu Plano de Manejo, que está em análise no CONSEMA e até o momento da elaboração deste trabalho, em 2021, não foi publicado. Utilizou-se para tanto o método monográfico, através de pesquisa bibliográfica, pesquisa documental, pesquisa de campo e observação. Constatou-se descontinuidade na elaboração e implementação de projetos e programas devido a constantes mudanças estruturais e políticas.
\end{abstract}

PALAVRAS-CHAVE: Áreas Protegidas, Plano de Manejo, Política Ambiental.

ABSTRACT: Protected areas have the mission of safeguarding the natural and cultural heritage. In order for them to fulfill their objectives, it is necessary to provide them with resources and planning and management instruments. In this work, we analyzed the planning and management processes of the Bananal Ecological Station (EEB), located in Serra da Bocaina in the State of São Paulo. The research was carried out from the period of the implementation of the Environmental Management Plan (PGA), published in 1998 until the conclusion of its Management Plan, which is under analysis at CONSEMA and until the time of elaboration of this work, in 2021, it was not published. For this purpose, the monographic method was used, through bibliographical research, documental research, field research and observation. There was a discontinuity in the design and implementation of projects and programs due to constant structural and political changes.

KEYWORDS: Protected Areas, Management Plan, Environmental Policy. 


\section{Introdução}

A criação de áreas protegidas (AP) está dentre as principais estratégias de salvaguardar o patrimônio natural e cultural. "Em termos de esforços de conservação por parte de governos, estão, sem dúvida, entre as "instituições mais importantes já concebidas" (BORRINI-FEYERABEND et al. 2017. p.13). No Brasil, são denominadas unidades de conservação (UC) e normatizadas pela Lei Federal № 9.985/2000, que instituiu o Sistema Nacional de Unidades de Conservação - SNUC (BRASIL, 2000). Segundo Prates e Irving (2015, p.53), "o SNUC constitui uma das propostas para a conservação da biodiversidade mais avançadas do mundo. Sua concepção transcende a proteção da biodiversidade, pois possibilita vários usos do solo e dos recursos naturais".

O aumento significativo na criação de novas áreas protegidas ocorreu nas últimas três décadas, notadamente nos países em desenvolvimento. A gestão desses espaços deve ser realizada de forma eficaz dentro de arcabouço legal e de governança adequada. Depende, ainda, de instrumentos e poderes, da participação, envolvimento e apoio de um conjunto diversificado de partes interessadas para alcançar a conservação da biodiversidade e as metas de desenvolvimento sustentável (THAPA, 2013; GELDMANN et al., 2015; BORRINI-FEYERABEND et al. 2017).

O futuro das áreas protegidas depende do alcance de ações governamentais para a implementação das políticas vigentes, bem como da integração e sinergia entre as políticas públicas. A capacidade de tomar decisões tem grande influência sobre a concretização dos objetivos das áreas protegidas, o compartilhamento de responsabilidades, os direitos, os custos e benefícios, bem como a construção e a manutenção de apoio - seja ele financeiro, político ou das comunidades que se relacionam com as áreas (PRATES; IRVING, 2015; BORRINI-FEYERABEND et al. 2017).

O Congresso de Áreas Protegidas da América Latina e Caribe realizado no Peru, em 2019, trouxe declarações, que expõem a necessidade do fortalecimento dos sistemas nacionais, gerenciamento eficaz além de mais financiamento (IUCN, 2019). O planejamento é fundamental para a gestão das unidades de conservação, pois somente através do que foi planejado será possível avaliar e monitorar a eficácia da gestão e consequentemente se as UCs estão de fato cumprindo seus objetivos. Segundo Borrini-Feyerabend et al. (2017, p. 11), "a gestão se refere a o que se faz em busca de determinados objetivos e os meios e ações para alcançá-los". A criação das AP é realizada pelo poder público e para orientar sua gestão e disciplinar seu uso é necessário um instrumento de planejamento, denominado Plano de Manejo. Este é o principal instrumento de gestão das UC e deve definir o zoneamento da área e estabelecer os programas de gestão. É elaborado a partir da realização de análises e diagnósticos dos elementos do meio físico, biótico e antrópico, num processo que deve ser integrado e participativo (BRASIL, 2000).

Planejamentos ambientais visam normatizar territórios complexos e, para tanto, necessitam estar suficientemente ligados à realidade em seus múltiplos aspectos. Visam interpretar o meio em relação à sua composição, estrutura, processo e função, como um todo e um contínuo no espaço (SANTOS, 2003). Segundo a autora, o planejamento é constituído por pesquisa, análise e síntese. A pesquisa visa reunir e organizar dados para facilitar sua 
interpretação. Os dados são avaliados para atingir a compreensão do meio estudado. A síntese refere-se à aplicação dos conhecimentos alcançados para a tomada de decisão.

Entender e aprimorar a governança é fundamental para a conservação eficaz. Trata-se do resultado de processos em que autoridade e responsabilidade são desenvolvidas e exercidas ao longo do tempo. É definida pela história, cultura e interação entre atores e instituições locais. Como demonstra a IUCN,

A governança diz respeito às instituições e aos processos pelos quais os detentores de direitos interessados diretos exercem influência e tomam decisões que afetam a área protegida. Vários instrumentos podem ser usados, entre eles planos de manejo, para estabelecer prioridades e um sistema de zoneamento, planejar o momento de uso de um recurso, abrir ou fechar o acesso a uma área e permitir ou não uma atividade" (BORRINIFEYERABEND et al. 2017. p. 21).

O Brasil apresenta seis diferentes biomas com alta biodiversidade e que passaram por diferentes processos de ocupação. Historicamente, o progresso humano derivou da exploração dos recursos biológicos com grande importância na economia do país (ARAÚJO, 2012). A Serra da Bocaina, área de etudo deste trabalho, sofreu processo de degradação bastante acentuado desde a época cafeeira, quando Bananal representou um dos grandes centros produtores. Posteriormente, foi explorada para a produção de carvão vegetal que abastecia siderúrgicas locais (SÃO PAULO, 1998). Devido à proximidade de grandes centros urbanos (150km do Rio de Janeiro e $300 \mathrm{~km}$ de São Paulo), a região é alvo de práticas predatórias onde somente um sistema de áreas protegidas pode conter esse processo (SÃO PAULO, 2010).

No entorno existem outras unidades de conservação, como o Parque Nacional da Serra da Bocaina, administrado pelo Instituto Chico Mendes de Conservação da Biodiversidade (ICMBio). Ambos fazem parte do Mosaico Bocaina, que compreende um total de $12 \mathrm{UC}$ de proteção integral e uso sustentável abrangendo 09 municípios. O Mosaico Bocaina foi instituído pela Portaria MMA no 349, de 11 de dezembro de 2006 (BRASIL, 2006). Reúne em seu território unidades de conservação de âmbitos federal, estadual e municipal, localizadas no Vale do Paraíba do Sul, litoral norte do Estado de São Paulo e litoral sul do Estado do Rio de Janeiro. O objetivo de um mosaico é estimular a gestão integrada de unidades de conservação de uma mesma região (SÃO PAULO, 2011). Este conceito tem como premissa a abordagem sistêmica proposta pelo SNUC, entretanto, como afirma Araújo (2012), a contribuição de cada UC e de cada categoria de manejo ainda é planejada de forma isolada. Segundo o autor, o grande desafio para os órgãos responsáveis pelas áreas protegidas será o de modernizar a gestão, fazendo com que avancem em direção à integração e qualidade.

Uma política pública passa pela percepção de um problema, pela necessidade da tomada de decisão, pela definição de objetivos e pelos meios de alcançá-los (NOGUEIRA, 2006). A vontade política pode ser constatada quando 
existem efetivas ações do poder público tais como comprometimento dos recursos orçamentários, incentivo a pesquisas, implementação de ações com eficiência e eficácia, entre outros (LEONEL et al. 2011).

Este trabalho teve como objetivo analisar os processos de planejamento e gestão da Estação Ecológica de Bananal (EEB), localizada na Serra na Bocaina no município de Bananal. A unidade de conservação está sob a gestão da Fundação Florestal (FF), instituição vinculada a Secretaria de Infraestrutura e Meio Ambiente do Estado de São Paulo (SIMA). O primeiro instrumento de planejamento da UC foi o Plano de Gestão Ambiental (PGA), publicado em 1998, elaborado no âmbito do Projeto de Preservação da Mata Atlântica (PPMA). Em 2011, teve início a elaboração do seu Plano de Manejo, que foi interrompido em 2012 e retomado em 2019. No momento sua versão final está em análise no CONSEMA e disponível para consulta no site da Fundação Florestal.

\section{Material e Métodos}

\section{Caracterização da área de estudo}

A área de abrangência do estudo foi a Estação Ecológica de Bananal, localizada no extremo leste do Estado de São Paulo. Originalmente designada como Reserva Florestal do Estado em 03/04/1964, segundo o Decreto no 43.193 e depois declarada Estação Ecológica de Bananal, de acordo com o Decreto no 26.890 de 12/ 03 /1987(SÃO PAULO, 1998). Localiza-se em uma região de relevo acentuado na Serra da Bocaina, que apresenta picos de até 2.132 metros. A vegetação é caracterizada por Floresta Ombrófila Densa e Floresta Ombrófila Alto Montana e uma das características mais marcantes é a grande quantidade e variedade de pteridófitas e bromélias. Além de apresentar alta diversidade quanto à flora, também abriga fauna que inclui espécies endêmicas e ameaçadas de extinção (SÃO PAULO, 1998).

No perímetro urbano de Bananal há inúmeros casarões típicos da "era do café", muitos são tombados pelo Conselho de Defesa do Patrimônio Histórico, Arqueológico, Artístico e Turístico do Estado (Condephaat) com grande potencial turístico (SÃO PAULO, 1998). A área rural de Bananal é formada por pequenas propriedades agrícolas, muitas das quais atualmente utilizadas como áreas de recreio. A atividade predominantemente é a pecuária de leite, plantio de braquiária, cana-de-açúcar e sorgo para os animais (SÃO PAULO, 2011).

No interior da UC estão as três últimas quedas da Cachoeira Sete Quedas formada pelo Rio das Cobras. Como patrimônio histórico possui um trecho da "Trilha do Ouro - Estrada do Ariró", construída por escravos no século XIX. Essa era utilizada para o transporte de mercadorias entre as minas do interior e o litoral do Brasil, sendo por ali escoado parte do ouro para ser transportado por via marítima para a Europa. É calçada de pedras alinhadas e niveladas por onde passavam as mulas cargueiras (SÃO PAULO, 1998). Em ambos os atrativos é permitida a visitação com finalidade de Educação Ambiental e pesquisa. As Figuras 1 e 2 apresentam os atrativos da UC. 


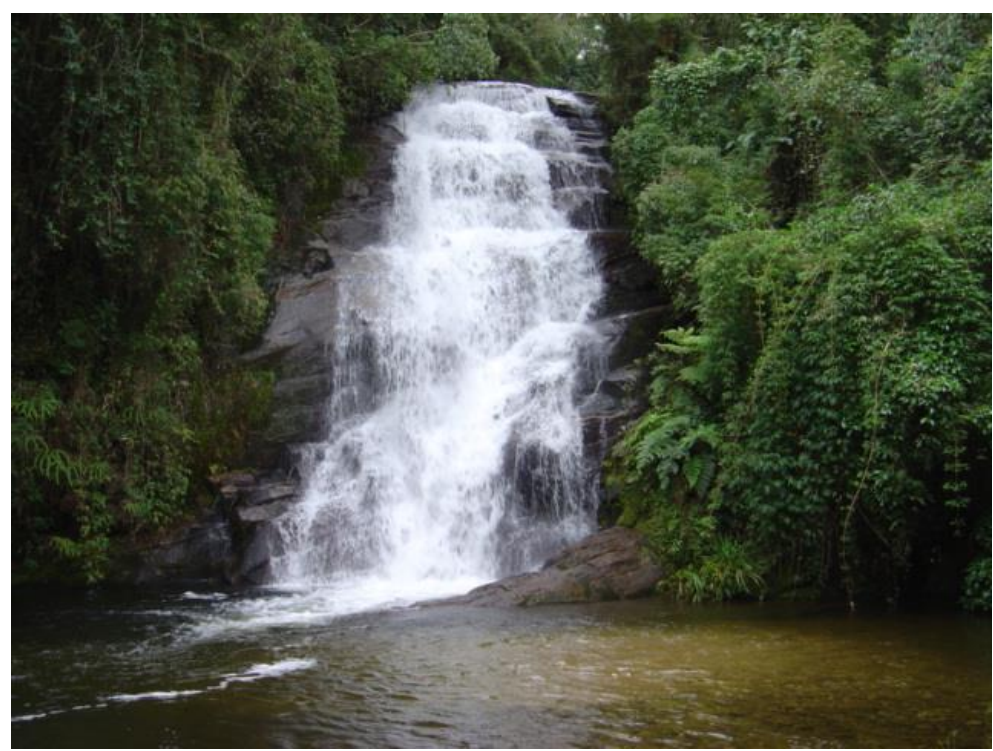

Figura 1. Cachoeira Sete Quedas.

Figure 1. Seven Falls Waterfall.

Fonte: As autoras (2011).

Source: By the authors (2011).

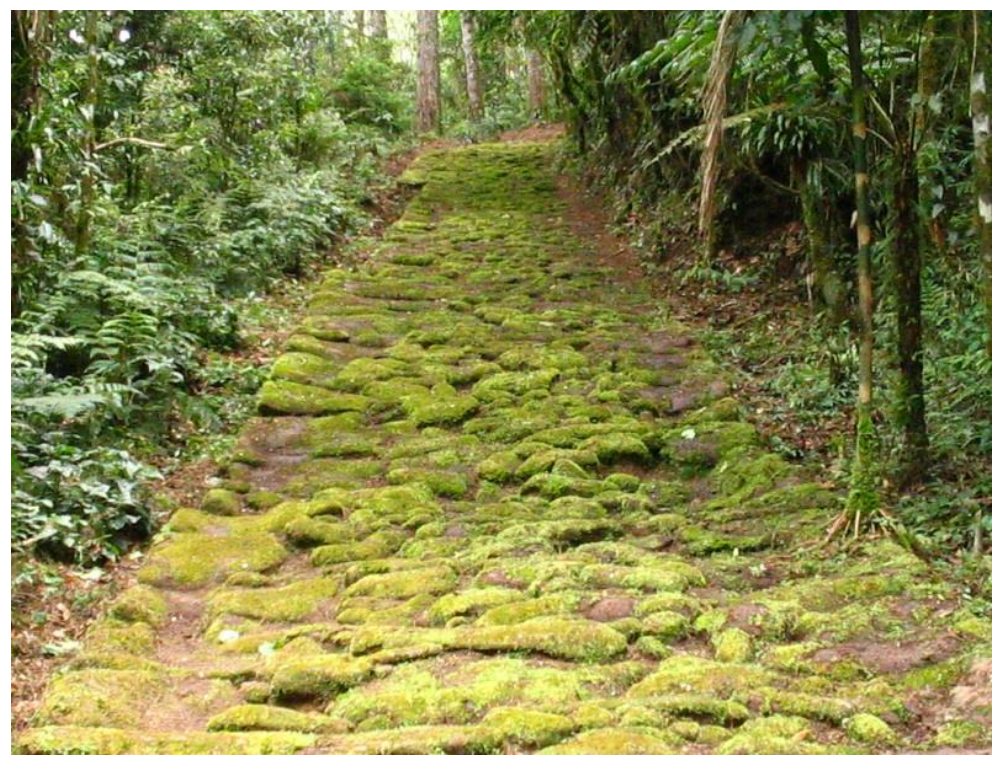

Figura 2. Triha do Ouro.

Figure 2: Trail of Gold.

Fonte: As autoras (2011).

Source: By the authors (2011).

A gestão da EEB esteve a cargo do Instituto Florestal (IF) desde a sua criação, em 1964, até o ano de 2006. Com a edição do decreto que instituiu o Sistema Estadual de Florestas - SIEFLOR a gestão foi transferida para a Fundação Florestal (FF). Ambas as instituições estão vinculadas à Secretaria de Infraestrutura e Meio Ambiente do Estado de São Paulo (SIMA) (SÃO PAULO, 2006). Atualmente, o IF é o responsável pela realização e autorização das pesquisas nas áreas protegidas do Estado, porém foi aprovada uma Lei Estadual que prevê sua extinção.

Esta pesquisa foi realizada através do método monográfico ou estudo de caso. Este consiste no estudo de determinados indivíduos, profissões, 
condições, instituições, grupos ou comunidades, com a finalidade de obter generalizações (MARCONI; LAKATOS, 2003). Segundo Pradavov e Freitas (2013, p.39), "o processo de pesquisa visa a examinar o tema selecionado de modo a observar todos os fatores que o influenciam, analisando-o em todos os seus aspectos". Para Newing (2011), os estudos de caso visam a uma compreensão detalhada do objeto de pesquisa, a fim de ampliar a compreensão sobre o tema observando fenômenos de forma concreta. Segundo a autora, a escolha do estudo de caso inclui a avaliação de aspectos práticos como a acessibilidade do local, contatos e infraestutura de apoio, por exemplo. Tais condições favoráveis permitiram a realização desta pesquisa.

As técnicas utilizadas para a realização da pesquisa foram:

- Pesquisa bibliográfica sobre os temas: planejamento ambiental, gestão e unidades de conservação. Os portais de pesquisa utilizados foram: Scielo e Periódocos CAPES. As palavas-chaves foram: "Áreas protegidas", "planejamento ambiental", "plano de Manejo" e "gestão" nas línguas portuguesa e inglesa.

- Pesquisa documental com leitura de documentos, legislação e relatórios;

- Consulta ao processo no arquivo morto da Secretaria de Meio Ambiente do Projeto de Preservação da Mata Atlântica - PPMA;

- Participação nas reuniões e oficinas realizadas para elaboração do Plano de Manejo - fase 1 (2011);

- Consulta do Plano de Manejo concluído e em análise no CONSEMA (2021).

\section{Resultados e Discussão}

De acordo com o SNUC, dentre as categorias de unidade de conservação de Proteção Integral estão as Estações Ecológicas, objeto de análise deste artigo. Tem como como objetivo a preservação da natureza e a realização de pesquisas científicas e é permitida a visitação com objetivo educacional (BRASIL, 2000). Para nortear sua gestão é necessário a elaboração de um Plano de Manejo, instrumento de planejamento de abordagem interdisciplinar. Tem como pressuposto o conhecimento da área e suas especificidades alcançado através de diagnósticos. De acordo com Santos (2003), este constrói cenários que apontam as potencialidades, fragilidades, acertos e conflitos. Essas observações permitem inferir um conjunto de alternativas, que tratam da solução dos impactos, das fragilidades, da reabilitação de paisagens, do desenvolvimento das potencialidades, do atendimento aos anseios sociais, entre outras.

Dentre os resultados do PM está o zoneamento, que sintetiza o resultado dos estudos e propostas. Consiste na divisão de uma área em porções territoriais, obtida pela avaliação dos atributos mais relevantes e de suas dinâmicas. Cada setor é apresentado como uma "área homogênea", ou seja, uma zona delimitada no espaço e possuindo estrutura e funcionamento semelhantes. Possui alto grau de associação dentro de si mesma, com variáveis solidamente ligadas, mas significativa diferença entre ela e os outros setores 
(SANTOS, 2003). Cada zona possui regramento específico com maior ou menor restrição. As zonas de uso extensivo, por exemplo, são aquelas onde são implantadas trilhas interpretativas. Já as zonas intangíveis são aquelas que devem ficar intactas e a pesquisa científica é rigorosamente controlada. Os planos de manejo, assim como os conselhos, são instrumentos de apoio à gestão legalmente obrigatórios para unidades de conservação. Entretanto, observa-se que muitas UCs não os possuem. Há casos em que planos são elaborados, mas não saem do papel e conselhos são instituídos apenas como medida administrativa e burocrática, sem periodicidade de reuniões e compartilhamento de tomada de decisão sobre a área.

A elaboração dos PMs como instrumento de gestão de UCs não constituiu tarefa finalizada. De acordo com Medeiros e Pereira (2011), é um processo que necessita de aprendizado e amadurecimento dos órgãos gestores, que possibilitarão a revisão dos procedimentos e orientações técnicas mais adequadas. A construção dos PMs no Brasil possui diversas fases, que vêm se aprimorando ao longo do tempo, conforme conhecimento acumulado. De acordo com Medeiros e Pereira (2011), a primeira fase ocorreu com a edição do decreto de regulamentação de parques em 1979. A segunda foi desenvolvida pelo IBAMA em 1996, com a publicação do "Roteiro Metodológico para o Planejamento de Unidades de Conservação de Uso Indireto" e a terceira com a publicação do "Roteiro metodológico de planejamento - Parques Nacionais, Reserva Biológica, Estação Ecológica", em 2002. Em 2018, foi lançado a última versão pelo ICMBio, "Roteiro metodológico para elaboração e revisão de planos de manejo das unidades de conservação federais" e, no mesmo ano, no Estado de São Paulo, o "Roteiro Metodológico para Elaboração de Planos de Manejo das Unidades de Conservação do Estado de São Paulo".

Considerava-se que os planos de manejo elaborados no passado eram documentos extensos, que dedicam boa parte de seu conteúdo a aspectos descritivos da área e não propriamente aqueles voltados para o seu manejo (MEDEIROS; PEREIRA, 2011). Para os autores, as informações descritivas são elementos necessários, pois servem de base para a construção do zoneamento e dos programas de gestão. Contudo, não podem se constituir no plano de manejo em si. A tendência dos PMs atuais é de elaboração de diagnósticos mais sintéticos e objetivos com foco nas prioridades de gestão. A elaboração do Plano de Manejo da EEB teve início em 2011, com a realização de diagnósticos e oficinas participativas. Entretanto, devido a questões contratuais e reestruturação da Fundação Florestal, os trabalhos foram interrompidos, em 2012. Em 2019, foi retomado com base na nova metodologia e atualmente, em 2021, está em análise na CONSEMA.

\section{Planejamento e Gestão na Estação Ecológica de Bananal}

Para facilitar a compreensão histórica da gestão da EEB foi criada uma linha do tempo exibida na Figura 3. Esta apresenta os fatos relevantes ocorridos na unidade de conservação, em paralelo a evolução das principais leis ambientais que incidem sobre a área. Pode-se observar, que sua criação precede a importantes regulamentações como o Código Florestal, a Política Nacional de Meio Ambiente e a criação da Secretaria do Meio Ambiente, por exemplo. 


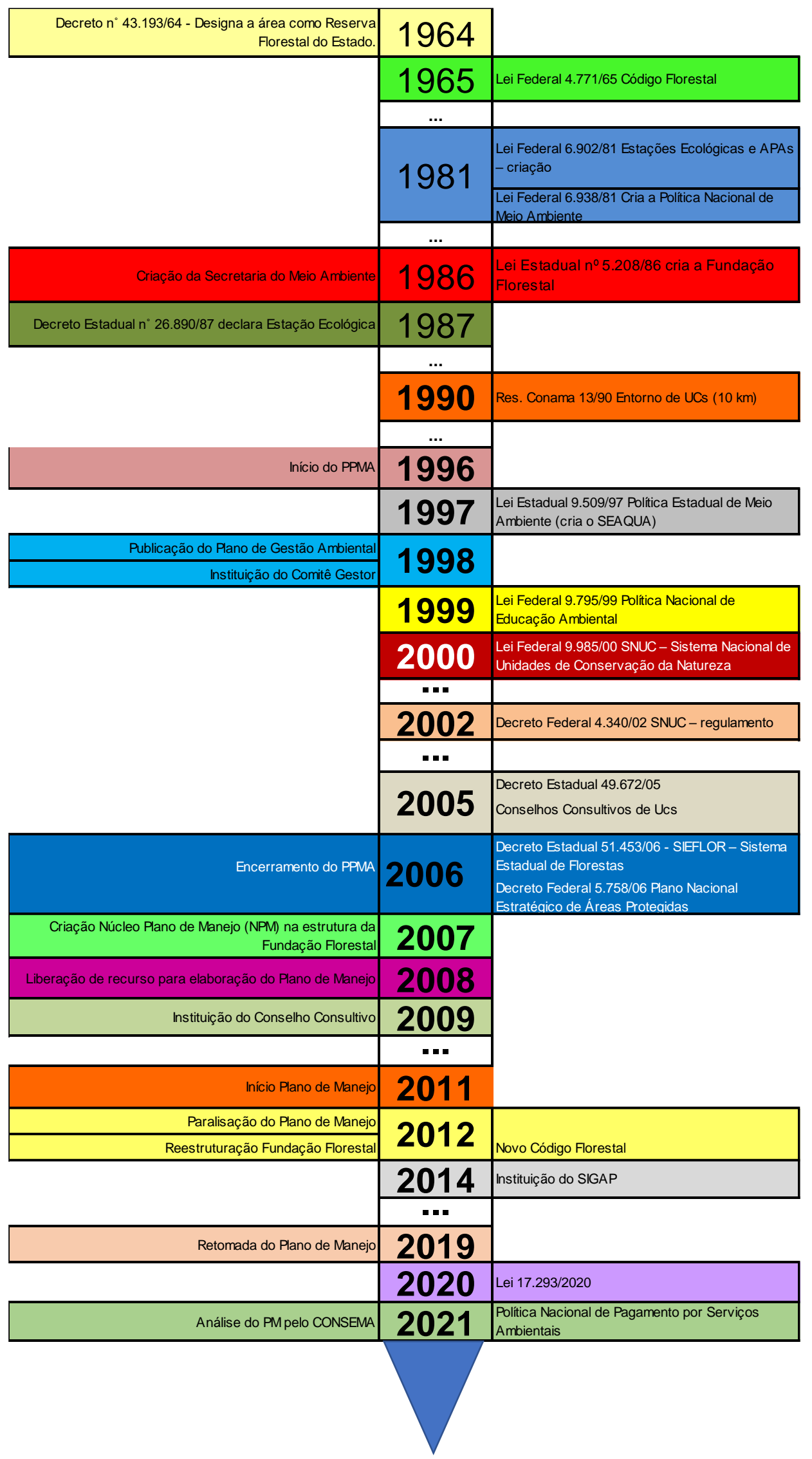

Figura 3. Linha do tempo da EE de Bananal.

Figure 3. Timeline of EE Bananal

Fonte: As autoras (2021)

Source: By the authors (2021). 
Assim como diversas áreas no Estado de São Paulo, a EEB foi criada como Reserva Florestal, em 1964. Em 1987, foi decretada como Estação Ecológica. Sua gestão, desde 2006, é atribuição da FF, com implantação do Sistema Estadual de Florestas - SIEFLOR. Esta foi concretizada através do Decreto Estadual ํㅜ 51.453, de 29/12/06 e alterado pelo Decreto Estadual oㅜ 54.079 , de 04/03/2009. Este Sistema é composto pelas unidades de proteção integral, unidades de uso sustentável e pelas unidades de produção (Estações Experimentais, Hortos e Viveiros Florestais) (SÃO PAULO, 2011).

A criação do SIEFLOR acarretou diversas mudanças no que concerne a gestão das unidades de conservação. Até então, a administração era realizada pelo Instituto Florestal, instituição centenária de pesquisa em áreas florestais. A Fundação Florestal foi criada em 1986, com objetivo de contribuir com a conservação, manejo e ampliação das florestas administradas pelo IF. Com sua criação, ao invés de contribuir, passa a ser a responsável pela gestão dessas Unidades de Conservação (REIS, 2011). Em 2014, através do Decreto № 60.302, foi instituído o Sistema de Informação e Gestão de Áreas Protegidas e de Interesse Ambiental do Estado de São Paulo - SIGAP: "como instrumento integrador, regulador e promotor das ações do Poder Público e da coletividade visando assegurar um meio ambiente ecologicamente equilibrado" (SÃO PAULO, 2014).

O Plano de Gestão Ambiental (PGA) foi o primeiro instrumento de planejamento da EEB, realizado no âmbito do Projeto de Preservação da Mata Atlântica - PPMA. Esse foi um contrato de cooperação financeira entre o governo brasileiro, através do Estado de São Paulo e a República Federal da Alemanha. Proporcionaram alocação de recursos financeiros substanciosos do banco estatal KfW Entwicklungsbank para aprimorar a fiscalização, o planejamento e implementação de algumas unidades de conservação do Estado, entre elas a EEB. No total foram destinados ao projeto 37,1 milhões de euros (SÃO PAULO, 2006). Destes 16,7 do Governo do Estado de São Paulo; 12,75 contribuição financeira KfW e 7,65 empréstimos KfW (SÃO PAULO, 2006). Foi assina-do, em 17 de dezembro de 1993, passando aproximadamente três anos para a formatação da coordenação, ajustes e atualizações da sua estrutura. Começou efetivamente no mês de setembro de 1996. Foi concluído em 2006 contemplan-do 20 Unidades de Conservação no Estado de São Paulo (MITLEWSKI, 2006, p.7).

Dentre os componentes do projeto estavam a elaboração dos Planos de Gestão Ambiental. Estes consistiam numa primeira fase do Plano de Manejo, em que foram realizadas análises a partir de dados secundários e identificadas necessidades na definição de estratégias para resolução de conflitos e formulação de propostas. O PPMA foi concebido com objetivo de estabilizar a cobertura vegetal de Mata Atlântica considerada um dos principais hotspots áreas de alta biodiversidade mais ameaçadas do planeta. Este conceito surgiu em 1988, porém seu impacto e dissiminação ocorreu a partir de 1999 (MITTERMEIER et al., 2005; SÃO PAULO, 2006). O PPMA foi estruturado com os seguintes componentes:

A - Fiscalização: tinha como objetivo a melhoria da fiscalização de toda a Mata Atlântica no Estado de São Paulo, visando à manutenção da sua atual cobertura;

B - Consolidação das unidades de conservação: Conservação e desenvolvimento sustentáveis de unidades de conservação selecionadas, assim como, ampliação de um viveiro de mudas, 
visando o cultivo de espécies de árvores nativas para o reflorestamento;

C - Apoio aos componentes A e B. Dentro deste componente foram elaborados os PGAs (MITLEWSKI, 2006).

Os PGAs foram elaborados para serem implantados em dois anos, concomitante à elaboração do Plano de Manejo. Dentre os relatórios elaborados na época, relatava-se que o alcance dos resultados propostos dependia de alguns pressupostos, dos quais os mais significativos eram:

-Prioridades que contemplavam o PPMA mantidas ao longo do projeto, independente de mudanças políticas e institucionais;

-Cumprimento do acordo pela contrapartida estadual ao longo do projeto;

-Disposição dos demais órgãos públicos, ONG's e sociedade civil em colaborar com o projeto (SÃO PAULO, 1998).

Destacava-se na elaboração desse projeto a inserção do tema participação, até então pouco ou nada difundido na cultura das UCs. Embora o conceito estivesse preconizado na legislação havia diferentes interpretações de como deveria ser realizado. Para se tornar efetivo deveria ser internalizado nas instituições através de capacitação e comprometimento, especialmente daqueles que devem alavancar o processo. Verificou-se que dentre as principais ações implementadas pelo PGA na EEB estava a construção da Sede para fiscalização, concluída em 2000. Essa foi planejada para abrigar os vigias e policiais florestais nas ações de fiscalização da UC. Com o tempo, tornou-se também base para todos os programas da UC, sendo utilizada para administração, atendimento a grupos e alojamento para pesquisadores. Outra ação importante foi a melhoria do acesso, com manutenção frequente da estrada a partir de 1999. Esta ação era realizada pela prefeitura, porém foi resultado de articulação da gestão da UC. Houve, também, aquisição de materiais como computadores, GPS, equipamentos de camping, rádio comunicadores, entre outros.

Como dito anteriormente, os PGAs foram elaborados para serem implantados em dois anos, concomitante à elaboração do Plano de Manejo. Porém, a elaboração do mesmo só teve início em 2011, mais de uma década após o planejado, com recurso de compensação ambiental. Para Mitlewski (2006), a estratégia principal para assegurar a sustentabilidade das atividades do PPMA era fortalecer a institucionalização de certas medidas cruciais, como por exemplo, os Conselhos Consultivos e os Planos de Manejo. Isso se refere à fixação das ações no sistema gerencial institucional e judicial, assegurando os recursos financeiros, físicos e humanos necessários.

Contatatou-se que após o encerramento do PPMA não ocorreu a elaboração dos PMs como preconizado pelo programa. Em 2007, foi criado dentro da estrutura organizacional da FF o Núcleo Planos de Manejo (NPM). Este tinha o intuito de organizar e supervisionar o processo envolvido na elaboração dos planos de manejo das UCs, pois a maior parte dessas não possuiam o documento. Surgiu em um momento em que a Secretaria de Meio Ambiente, elegeu o tema "Gestão de Unidades de Conservação" como um dos projetos prioritários da pasta, sendo dos principais objetivos a elaboração e aprovação dos planos de manejo (LEONEL et al. 2011). 
Para assegurar a efetividade das atividades foi subordinado diretamente à Direção Executiva, instância mais alta de decisão da Fundação Florestal. Esta estrutura institucional representava uma estratégia política e administrativa para agilizar e melhorar o processo de planejamento ambiental, dentre outras traçadas para o contexto das UC paulistas (LEONEL et al. 2011). O principal objetivo foi a padronização de procedimentos e alinhamento no processo de planejamento. O NPM centralizou as atividades desde a captação de recursos, elaboração do termo de referência, definição do modelo de contratação, gerenciamento do processo e fiscalização no cumprimento de prazos até aprovação no CONSEMA (LEONEL et al., 2011). O recurso para a EEB foi liberado em 2008 através de compensação ambiental. O início dos trabalhos ocorreu em maio de 2011 e foi planejado para ser executado em onze meses. A equipe foi formada por pesquisadores do Instituto Florestal (IF) e Instituto Geológico (IG), ambos vinculados à Secretaria do Meio Ambiente (SMA) e por consultores contratados. Sua realização seguiu as etapas padronizadas pelo NPM, que tinha como principal referência o Roteiro Metodológico do IBAMA (2002).

A maior parte do trabalho foi executada. O diagnóstico foi realizado através de informações secundárias e coleta de dados primários por meio da metodologia Avaliação Ecológica Rápida (ERA) (SAYRE et al., 2000). No que se refere à questão participativa foram realizadas três oficinas, que ocorreram nos meses de setembro, outubro e novembro de 2011. Nestas compareceram membros da prefeitura, associações, moradores do entorno, Polícia Ambiental e representantes da educação no Município. Os temas abordados foram Educação Ambiental, gestão, proteção e interação socioambiental.

A primeira oficina teve como objetivo compreender a identidade da EEB e do grupo; explicar a construção do plano de manejo; os temas; apresentar as equipes de estudo; as etapas de trabalho; os prazos, assim como conhecer a visão e expectativas. Foram levantados os pontos críticos; as alternativas atuais (em uso); o relacionamento com a UC e o papel da comunidade em relação ao plano de manejo. Visou também elaborar diagnóstico de ativos (potencialidades) e necessidades da EEB nos temas Proteção, Interação Socioambiental, Pesquisa e Manejo da Biodiversidade e Educação Ambiental. O público convidado incluiu a prefeitura, câmara de vereadores, delegacia de Polícia Civil, sindicato rural, rádio comunitária, moradores do entorno, representantes do Mosaico Bocaina, empresas locais, Universidade Federal Fluminense, ONGs locais, nas pessoas de seus representantes das áreas de Educação, Meio Ambiente, Agricultura, Turismo e sociedade em geral.

O acompanhamento dos trabalhos demonstrou que parte do tempo desta oficina foi destinado a explicar aos participantes do que se tratava o trabalho. Esclareceu-se as características da categoria Estação Ecológica, assim como suas restrições e o conceito de plano de manejo. Observou-se que estes eram desconhecidos pela maioria dos participantes. Este fato se explicava, pois havia distanciamento da UC com a comunidade, que só era "convocada" a participar em momentos específicos como a elaboração do PGA em 1998 e com o início o plano de manejo, por exemplo. Entre a realização desses dois projetos passaram-se mais de uma década. O levantamento dos ativos e necessidades da UC foram realizados utilizando metodologia denominada "os quatro níveis organizacionais". Estes se referiam aos: 
- recursos materiais (o que é de fato material e tangível, como a sede, o centro de visitantes, por exemplo.);

- processos (referia-se a dinâmica dos processos, aos formulários, aos adiantamentos e licitações, por exemplo);

- relações (as relações entre funcionários, instituições e departamentos, por exemplo) e

- cultura/valores (referia-se à identidade da unidade de conservação, aquilo em que se acredita).

Os trabalhos foram realizados por grupos temáticos. O tema proteção apresentou mais pontos críticos do que ativos, exceto nas relações. Havia parceria com a Polícia Ambiental e boa comunicação com entorno através de reuniões com moradores para planejamento da fiscalização. Deste modo, os pontos positivos compensavam os pontos críticos da UC. Os temas guarda-parque e porte de arma foram preocupantes, pois, a carreira foi extinta e os funcionários não podiam utilizar armas de fogo na fiscalização. Este fato gerou temor e desmotivação dos mesmos que em algumas situações se sentiam vulneráveis. Outra fragilidade era a questão das escalas que não condiziam com as necessidades da UC. De acordo com o depoimento de um funcionário, se fossem cumpridas de forma correta seria como "um restaurante que fecha na hora do almoço".

Em relação aos recursos naturais observou-se que a maioria dos pontos críticos estava nos processos e os ativos nos recursos como a existência de áreas conservadas, alto grau de endemismo e espécies raras, por exemplo. Houve destaque para geodiversidade da região, onde a variação de relevo resultava em diversidade de vários aspectos. A riqueza do patrimônio natural da EEB era o principal aspecto positivo.

Em relação à Educação Ambiental observou-se que o campo das relações era o mais evidente. Destacou-se o fato de Bananal ter sido colocado como destino turístico pelo governo federal e ser integrante do circuito Vale Histórico. Constatou-se, que por esse motivo existiam recursos, mas faltavam projetos para executá-los. Havia informalidade nos processos de informação. Os cursos de guias municipais não tinham módulo de Meio Ambiente. Houve debate sobre a regulamentação da carreira de monitor que difere do guia. De acordo com um participante "O processo educacional não é guiado e sim monitorado". Constatou-se, também, que havia muitas ações individuais que não eram institucionalizadas. No tema Interação Socioambiental observou-se que as relações foram mais evidentes. Discutiu-se também a falta de continuidade nas ações de gestão pública e dificuldade no funcionamento dos conselhos municipais. Novamente evidenciou-se que as parcerias eram individuais e não institucionais.

A segunda oficina teve como objetivo analisar e discutir os resultados parciais de campo trazidos pelos pesquisadores, aproximar os participantes da realidade da EEB e prepará-los para a futura formulação de propostas. Foram apresentados os resultados obtidos pela equipe técnica com a utilização de mapas temáticos e imagens e uma metodologia denominada word café, "método utilizado para conversas significativas sobre questões complexas, ancorado num conjunto de princípios para um ambiente seguro" (FERNANDES, 2015, p. 81). No segundo dia de oficina os participantes foram levados para UC, pois alguns não a conheciam. O próximo passo foi a elaboração de propostas. A Tabela 1 apresenta as contribuições agrupadas por tema. 
Tabela 1: Contribuições da Oficina 2 de planejamento participativo para elaboração do Plano de Manejo da Estação Ecológica de Bananal.

Table 1: Contributions from Workshop 2 on participatory planning for the preparation of the Bananal Ecological Station Management Plan.

\begin{tabular}{|c|l|}
\hline TEMA & \multicolumn{1}{c|}{ Propostas } \\
\hline \multirow{4}{*}{ Infraestrutura } & Criação de Centro de Informações no Município \\
\cline { 2 - 2 } & Construção de Centro de Visitantes \\
\cline { 2 - 2 } & Construção de alojamento para funcionários e visitantes \\
\cline { 2 - 2 } & Ampliação da Sede \\
\cline { 2 - 2 } & Aquisição de aparelhagem laboratorial \\
\hline \multirow{4}{*}{ Educação } & $\begin{array}{l}\text { Inclusão da EEB no currículo escolar da cidade com atividades de Educação } \\
\text { Ambiental }\end{array}$ \\
\cline { 2 - 2 } & Curso anual de brigada de incêndio com manutenção e troca de equipamentos \\
\cline { 2 - 2 } & Informação \\
\cline { 2 - 2 } Gestão de & Conscientização \\
\cline { 2 - 2 } Pessoas & Contratação de mais pessoas \\
\cline { 2 - 2 } Pesquisa & Segurança e fiscalização \\
\hline
\end{tabular}

Fonte: elaborado pelas autoras (2021).

Source: elaborated by the authors (2021).

A realização da terceira oficina teve como objetivo gerar propostas para os programas componentes do Plano de Manejo. Os participantes foram convidados a criar uma árvore de ideias. Foram distribuídas tarjetas em que deveria ser escrita uma ação/necessidade para o referido programa. Nesta oficina houve bastante contribuição dos participantes. A Talela 2 apresenta as contribuições elaboradas para o Programa de Educação Ambiental.

Tabela 2: Contribuições da Oficina participativa 3 do Plano de Manejo da EE Bananal - Programa de Educação Ambiental

Table 2: Contributions from Participatory Workshop 3 of the Bananal EE Management Plan -

Environmental Education Program.

\begin{tabular}{|c|c|c|c|}
\hline $\begin{array}{c}\text { Estruturação da Visitação } \\
\text { monitorada }\end{array}$ & $\begin{array}{l}\text { Educação Ambiental } \\
\text { inserida nas escolas }\end{array}$ & $\begin{array}{c}\text { Educação Ambiental } \\
\text { expandida }\end{array}$ & $\begin{array}{l}\text { Parceria com o } \\
\text { Município }\end{array}$ \\
\hline Divulgação da EBB & $\begin{array}{l}\text { Promoção de ações de } \\
\text { sustentabilidade nas } \\
\text { unidades escolares }\end{array}$ & $\begin{array}{l}\text { Estender os trabalhos de EA } \\
\text { para o entorno da EEB } \\
\text { (priorizar a bacia do Rio Turvo } \\
\text { e Bananal) }\end{array}$ & $\begin{array}{l}\text { Elaboração de Lei para } \\
\text { regulamentar EA no } \\
\text { Município }\end{array}$ \\
\hline $\begin{array}{l}\text { Criação de Material didático } \\
\text { nas escolas que seja } \\
\text { preparativo para visita de } \\
\text { campo na EEB }\end{array}$ & $\begin{array}{l}\text { Criação da semana da } \\
\text { EA nas escolas com } \\
\text { realização de concurso } \\
\text { de redação, gincanas, } \\
\text { palestras e teatros com } \\
\text { temas ambientais }\end{array}$ & $\begin{array}{l}\text { Conscientização dos } \\
\text { funcionários das fazendas do } \\
\text { entorno da EEB sobre o que é } \\
\text { uma Estação Ecológica }\end{array}$ & $\begin{array}{l}\text { Projeto de EA municipal } \\
\text { integrado (todas as } \\
\text { secretarias) }\end{array}$ \\
\hline $\begin{array}{l}\text { Ampliação da Infraestrutura } \\
\text { de recepção }\end{array}$ & $\begin{array}{l}\text { Visitação de alunos da } \\
\text { rede municipal e } \\
\text { apresentação da } \\
\text { biodiversidade e da } \\
\text { importância da UC e } \\
\text { entorno }\end{array}$ & $\begin{array}{l}\text { Parceria com proprietário do } \\
\text { entorno para ordenar visitação } \\
\text { na primeira queda da } \\
\text { cachoeira sete quedas }\end{array}$ & $\begin{array}{l}\text { Inserir as atividades de EA } \\
\text { na EEB no currículo } \\
\text { escolar de Bananal }\end{array}$ \\
\hline $\begin{array}{l}\text { Formalização de parcerias } \\
\text { com associações para } \\
\text { utilização de estruturas no } \\
\text { auxílio ao receptivo dos } \\
\text { visitantes na EEB }\end{array}$ & $\begin{array}{l}\text { Integração das } \\
\text { disciplinas no } \\
\text { desenvolvimento de } \\
\text { projetos na EEB }\end{array}$ & $\begin{array}{l}\text { Criação de grupo de } \\
\text { voluntários para apoiar a EEB } \\
\text { com palestras e ações } \\
\text { educativas }\end{array}$ & $\begin{array}{l}\text { Colocar em prática a } \\
\text { visitação monitorada dos } \\
\text { estudantes locais e de } \\
\text { outras cidades (capacitar } \\
\text { monitores locais) }\end{array}$ \\
\hline $\begin{array}{l}\text { Criação de centro de } \\
\text { visitantes da EEB com sala } \\
\text { para atividades de EA. }\end{array}$ & $\begin{array}{l}\text { Comemorar, sensibilizar } \\
\text { e preservar o ambiente. } \\
\text { Ex.: } 21 \text { dia da árvore. }\end{array}$ & $\begin{array}{l}\text { Desenvolvimento de projetos } \\
\text { que beneficiem a região. Ex.: } \\
\text { viveiros para desenvolver } \\
\text { mudas de árvores nativas para } \\
\text { serem plantadas nas margens } \\
\text { dos rios formando mata ciliar }\end{array}$ & $\begin{array}{l}\text { Criação de calendário } \\
\text { municipal de eventos }\end{array}$ \\
\hline
\end{tabular}

Continua... 
...continuação.

\begin{tabular}{|l|l|l|l|}
\hline $\begin{array}{c}\text { Estruturação da Visitação } \\
\text { monitorada }\end{array}$ & $\begin{array}{c}\text { Educação } \\
\text { Ambiental inserida } \\
\text { nas escolas }\end{array}$ & $\begin{array}{c}\text { Educação Ambiental } \\
\text { expandida }\end{array}$ & \multicolumn{1}{|c|}{ Parceria com o Município } \\
\hline $\begin{array}{l}\text { Capacitação da equipe da } \\
\text { EEB para realização de }\end{array}$ & $\begin{array}{l}\text { Disseminar a importância } \\
\text { da EEB aos pequenos, } \\
\text { médios e grandes agentes } \\
\text { econômicos (economia } \\
\text { autossustentável) }\end{array}$ & $\begin{array}{l}\text { Utilização da EEB como atrativo } \\
\text { turístico científico e parceiro da } \\
\text { Secretaria de Educação, Turismo } \\
\text { e Meio Ambiente }\end{array}$ \\
\hline & $\begin{array}{l}\text { Parcerias com prefeituras } \\
\text { do Vale histórico para } \\
\text { participação das escolas no } \\
\text { projeto de EA. }\end{array}$ & $\begin{array}{l}\text { Implantação de sistema de coleta } \\
\text { seletiva na EEB e moradias do } \\
\text { entorno }\end{array}$ \\
\hline & & $\begin{array}{l}\text { Lixos tecnológicos (diminuir } \\
\text { consumismo) orientar o destino } \\
\text { dos resíduos }\end{array}$ \\
\hline & & $\begin{array}{l}\text { Articulação para transporte dos } \\
\text { alunos para a à EEB }\end{array}$ \\
\hline & & $\begin{array}{l}\text { Criação de Centro receptivo de } \\
\text { informações na cidade de } \\
\text { Bananal }\end{array}$ \\
\hline
\end{tabular}

Houve, ainda, uma oficina de pesquisa direcionada para pesquisadores que atuaram na elaboração do Plano de Manejo e membros de instituições de pesquisa convidados. Compareceram, também, representantes do conselho consultivo das instituições Polícia Ambiental de Bananal e Sindicato Rural. Realizou-se uma apresentação com síntese dos diagnósticos em painéis. Posteriormente, os participantes foram divididos em grupos de trabalho (GT) para discutirem e criarem uma matriz com propostas sobre linhas de pesquisa, parcerias e infraestrutura. O GT Linhas de pesquisa foi conduzido por representates das universidades; o GT Parcerias, pelo Conselho Consultivo e o GT Infraestrutura, por servidores do SIEFLOR. A Tabela 3 apresenta as contribuições elaboradas pelos participantes e cada coluna representa um dos grupos.

Tabela 3. Contribuições da Oficina de Pesquisa para elaboração do Plano de Manejo da Estação Ecológica de Bananal.

Table 3. Contributions from the Research Workshop for the preparation of the Bananal Ecological Station Management Plan.

\begin{tabular}{|c|c|c|}
\hline GT1. Linhas de pesquisa & GT2. Parcerias & GT3. Infraestrutura \\
\hline $\begin{array}{l}\text { Pesquisar fluxo da Biota entre UCs } \\
\text { (Bocaina, Cunhambebe e corredores) }\end{array}$ & $\begin{array}{l}\text { Ampliar oferta de alojamento para } \\
\text { pesquisadores através de cadastros de } \\
\text { proprietários do entorno formalizado por termo } \\
\text { de compromisso. }\end{array}$ & $\begin{array}{l}\text { Instalação de estações } \\
\text { meteorológicas com garantia de } \\
\text { manutenção e operacionalização }\end{array}$ \\
\hline $\begin{array}{l}\text { Estudos que expliquem a presença de } \\
\text { muitas espécies endêmicas na EEB e } \\
\text { ZA/corredores }\end{array}$ & $\begin{array}{l}\text { Exposição da EEB no Museu de Zoologia da } \\
\text { USP }\end{array}$ & $\begin{array}{l}\text { Brigada de incêndio e } \\
\text { equipamentos }\end{array}$ \\
\hline $\begin{array}{l}\text { Estudos com interferência } \\
\text { experimental. Ex.: restauração, } \\
\text { dinâmica microclimática, relação } \\
\text { solo/vegetação }\end{array}$ & $\begin{array}{l}\text { Instituição do dia da Estação Ecológica de } \\
\text { Bananal com festa, exposição e pic-nic. }\end{array}$ & $\begin{array}{l}\text { Manutenção de estradas e pontes } \\
\text { municipais }\end{array}$ \\
\hline $\begin{array}{l}\text { Pesquisas em pagamento por serviços } \\
\text { ecossistêmicos }\end{array}$ & $\begin{array}{l}\text { Integração da EEB nos planos nacionais para } \\
\text { conservação de espécies }\end{array}$ & $\begin{array}{l}\text { Áreas adequadas para elaboração } \\
\text { da pesquisa (laboratórios) e } \\
\text { alojamentos separados. }\end{array}$ \\
\hline $\begin{array}{l}\text { Pesquisar Impactos do turismo no } \\
\text { entorno da EEB (pousada, hotéis e } \\
\text { atrativos) }\end{array}$ & $\begin{array}{l}\text { Divulgação da pesquisa à funcionários e } \\
\text { comunidade via seminários e panfletos. }\end{array}$ & \\
\hline $\begin{array}{l}\text { Classificação e categorização } \\
\text { climática da área com coleta de dados } \\
\text { sistemáticos. }\end{array}$ & $\begin{array}{l}\text { Divulgação da pesquisa para gestor, } \\
\text { funcionários e até comunidade via } \\
\text { apresentações/seminários/panfletos. }\end{array}$ & \\
\hline \multirow[t]{3}{*}{$\begin{array}{l}\text { Definição e discussão de indicadores } \\
\text { de monitoramento }\end{array}$} & $\begin{array}{l}\text { Simpósio de apresentação de trabalhos } \\
\text { realizados na UC. }\end{array}$ & \\
\hline & $\begin{array}{l}\text { Publicação em revistas nacionais como } \\
\text { Biotaneotrópica, Revista do IF. }\end{array}$ & \\
\hline & Plano de relacionamento entre $\mathrm{UC} \mathrm{e}$ & \\
\hline
\end{tabular}


O Programa de Pesquisa e Manejo das Unidades de Conservação é extremamente relevante, pois a pesquisa está entre os principais objetivos de uma UC, especialmente de uma Estação Ecológica. Este trabalho revelou que pouca prioridade tem se dado a este programa em temos de planejamento, investimento e parceria. É fundamental que as instituições responsáveis se empenhem em aprimorar o desenvolvimento de pesquisas, pois o conhecimento gerado e acumulado é fundamental como subsídio à gestão e às tomadas de decisão.

Por fim realizou-se uma oficina destinada a discutir o zoneamento da UC. Está oficina foi precedida por uma reunião técnica onde foram construídas as propostas baseadas nos levantamentos do meio físico, biótico e antrópico, que orienta a criação da zona de amortecimento. Deste modo, esta oficina teve como objetivo apresentar e esclarecer a proposta técnica das possíveis zonas, assim como discutir o regramento de cada uma delas, especialmente da zona de amortecimento, que possui influência direta nos moradores do entorno.

Este foi o último evento realizado na primeira fase da elaboração do plano de manejo, que foi interrompido em 2012. Os trabalhos foram retomados e concluídos em 2019 e até a elaboração deste trabalho (outubro de 2021), encontrava-se em análise no CONSEMA. Observou-se que na gestão pública é recorrente a descontinuidade de programas e projetos, especialmente com mudanças organizacionais. A expressão "continuidade e descontinuidade" administrativa refere-se aos dilemas, práticas e contradições que surgem na administração pública a cada mudança de governo e a cada troca de dirigentes (SPINK, 1987). De acordo com Nogueira (2006) a descontinuidade em programas ou projetos acarreta inúmeros prejuízos como desperdício de recursos, a perda de memória e saber institucional, além do desânimo das equipes.

No discurso presente no cotidiano de fundações, secretarias, autarquias e empresas públicas, e por vezes reforçado pela imprensa, quando há troca de governo, a descontinuidade administrativa é dada como fato (NOGUEIRA, 2006). Porém, este não é o caso do Estado de São Paulo, que é governado pelo mesmo partido político a mais de duas décadas, mas apresenta muitas mudanças na estrutura das instituições ambientais. A continuidade de projetos e programas pode ser favorecida pela qualidade e mérito técnico da ação, promoção de parcerias, participação de diversos atores e planejamento com visão de longo prazo (NOGUEIRA, 2006). Porém, não é o que se tem observado na política ambiental do Estado. A paralisação de programas e projetos está relacionada à descontinuidade por mudanças nas estruturas organizacionais, na mudança recorrente dos cargos comissionados e mudança de prioridades.

Para Esquinsani (2009), projetos e ações desenvolvidas pela administração que termina, não raro, são engavetados e esquecidos. A ideia de compromisso com a "mudança" em relação ao que o outro (administração, secretário, grupo...) fazia, por vezes termina em projetos abortados. A retomada da elaboração do PM ocorreu em 2019, com base no novo Roteiro Metodológico publicado pela Fundação Florestal (SÃO PAULO, 2019). Os trabalhos foram realizados a partir dos diagnósticos elaborados na primeira fase que ocorreu em 
2011. A Tabela 4 apresenta as etapas realizadas para conclusão do PM em 2019.

Tabela 4: Etapas da retomada da elaboração do Plano de Manejo da Estação Ecológica de Bananal

Table 4: Steps for resuming the elaboration of the Bananal Ecological Station Management Plan.

\begin{tabular}{|c|c|c|}
\hline Data & Etapa & Pauta \\
\hline \multirow[t]{2}{*}{$14 / 02 / 2019$} & \multirow[t]{2}{*}{ Reunião de Planejamento } & Mapeamento de atores \\
\hline & & Mapa situacional \\
\hline \multirow{4}{*}{$28 / 03 / 2019$} & \multirow{4}{*}{$\begin{array}{l}\text { Retomada da elaboração do } \\
\text { Plano de Manejo }\end{array}$} & Pauta e Participação Pública no Plano de Manejo \\
\hline & & $\begin{array}{l}\text { Concepção Metodológica para elaboração do Plano } \\
\text { de Manejo }\end{array}$ \\
\hline & & Apresentação da Estação Ecológica de Bananal \\
\hline & & Árvore de Problemas \\
\hline \multirow{6}{*}{$21 / 05 / 2019$} & \multirow{6}{*}{ Etapa de zoneamento } & $\begin{array}{l}\text { Pauta e Avaliação da Participação Pública no Plano } \\
\text { de Manejo }\end{array}$ \\
\hline & & Concepção Zoneamento para Estação Ecológica \\
\hline & & $\begin{array}{c}\text { Proposta Zoneamento da Estação Ecológica de } \\
\text { Bananal }\end{array}$ \\
\hline & & $\begin{array}{c}\text { Painéis de Diagnóstico: Meio Físico, biótico, } \\
\text { antrópico, jurídico }\end{array}$ \\
\hline & & Contribuições no mapa \\
\hline & & Contribuições sistematizadas \\
\hline \multirow{3}{*}{$19 / 07 / 2019$} & \multirow{3}{*}{$\begin{array}{c}\text { Etapa de Programas de } \\
\text { Gestão }\end{array}$} & $\begin{array}{c}\text { Pauta e Avaliação da Participação Pública no Plano } \\
\text { de Manejo }\end{array}$ \\
\hline & & Concepção de Programas de Gestão \\
\hline & & Contribuições sistematizadas \\
\hline $25 / 07 / 2019$ & $\begin{array}{l}\text { Etapa Devolutivas e } \\
\text { Manifestação do Conselho }\end{array}$ & Apresentação das Devolutivas \\
\hline $18 / 09 / 2019$ & $\begin{array}{l}\text { Etapa Devolutivas II e } \\
\text { Manifestação do Conselho }\end{array}$ & Manifestação final do Conselho Consultivo \\
\hline
\end{tabular}

Fonte: São Paulo, 2021 (adaptado).

Source: São Paulo, 2021 (adapted).

Como mencionado os diagnósticos e oficinas participativas foram realizados na primeira fase (2011). Com a retomada dos trabalhos houve atualização dos dados e novas oficinas participativas. Observou-se, que as fragilidades e demandas apresentadas permaneceram as mesmas como falta de funcionários, presença de animais domésticos, caça, poucas parcerias formais, falta de informações, presença de jipeiros, entre outras. A matriz de planejamento dos PMs anteriores era formada por: objetivo, diretrizes, linhas de ação e indicadores. O modelo atual traz, além destes itens, condicionantes, como disponibilidade orçamentária, por exemplo, além de indicar as responsabilidades e parcerias. Considera-se que houve avanço em relação a estes aspectos, pois a implementação do PM depende da capacidade institucional de executar as ações propostas. Vale mencionar, que em 2019, houve outra significativa alteração na gestão ambiental do Estado, com uma reestruturação administrativa, que integrou as Secretarias de Meio Ambiente (SMA), do Saneamento e Recursos Hídricos (SRH) e da Energia e Mineração (SEM), formando a Secretaria de Infraestrutura e Meio Ambiente (SIMA).

Em 2020, foi aprovada a Lei № 17.293 que "Artigo $1^{\circ}$ - Fica o Poder Executivo autorizado a promover a extinção das seguintes entidades descentralizadas", entre as quais o Instituto Florestal, responsável pela condução das pesquisas nas UCs. Essas ações têm sido consideradas temerárias por especialistas, pois tendem enfraquecer a agenda ambiental no Estado. A pesquisa nas UCs é fundamental para dar subsídios à gestão e a extinção dos Institutos acarretará numa perda inestimável do patrimônio acumulado ao longo de décadas. De acordo com Bocuhy (2021), "coloca em 
risco o futuro da qualidade ambiental, baseando suas ações primordialmente nas finanças, mirando as áreas protegidas apenas sob a ótica de possibilidades de negócios". Para reverter este processo foi movida, contra o Governo Estadual, uma Ação Direta de Inconstitucionalidade, pela Associação dos Pesquisadores Científicos do Estado de São Paulo (APqC) e outras instituições. Houve também moção assinada por aproximadamente 300 signatários dirigida ao governador. "O documento qualifica a extinção dos institutos como um 'retrocesso ambiental' sem precedentes" (TEIXEIRA, 2021). Para substituir os centenários institutos 0 governo criou o Instituto de Pesquisas Ambientais (IPA), através do Decreto no 65.796, de 16 de junho de 2021. Segundo a APqC, "Os institutos possuem missões distintas que não justificam a sobreposição de suas atribuições. Tal medida, tomada pelo governo sem consulta à comunidade científica, tem sido alvo de protestos da sociedade civil organizada" (TEIXEIRA, 2021).

\section{Considerações Finais}

A falta de continuidade de projetos e programas é dos principais problemas da administração pública, pois implica em desperdício de recursos, desmotivação de pessoas e desarticulação com entidades parceiras e descompromisso com uma política ambiental séria e eficiente. A análise dos processos de panejamento da EEB evidenciam este fato. O Plano de Gestão Ambiental ocorreu em 1998, o início do Plano de Manejo em 2011, com retomada em 2019 e atualmente aguarda aprovação no CONSEMA, em 2021. A ausência de planos de manejo e conselhos consultivo e deliberativo nas unidades de conservação brasileiras é uma realidade, que demonstra que o planejamento esteve historicamente fora dos processos de gestão ambiental. $\mathrm{Na}$ última década essa realidade vem se alterando com a elaboração de planos mais "enxutos", mas é necessário avançar nos processos de monitoramento e avaliação.

A eficiência da gestão das unidades de conservação só se concretizará quando o planejamento de longo prazo for incorporado no cotidiano das UCs. A cultura da participação deverá ser incentivada e apoiada para que conselhos passem a fazer parte permanente da sua estrutura. É necessário que se estabeleça uma relação em que os indivíduos passem a compreender o real significado e a importância das unidades de conservação. É fundamental que passem a ser protagonistas dos rumos das UCs fazendo cobranças para que o Estado cumpra seu papel de mantenedor dessas áreas investindo em pesquisa, fiscalização, manejo e monitoramento.

\section{Referências}

ARAÚJO, M, A, R. A biodiversidade e sua importância. In: NEXUCS (org.). Unidades de conservação no Brasil: o caminho da Gestão para Resultados. São Carlos: RiMa Editora, 2012.

BORRINI-FEYERABEND, G., N. et al. Governança de Áreas Protegidas: da compreensão à ação. Série Diretrizes para melhores Práticas para Áreas Protegidas, No. 20, Gland, Suiça: UICN. xvi + 124pp, 2017. 
BRASIL. Ministério do Meio Ambiente. Roteiro Metodológico de Planejamento do IBAMA. Brasília, DF. p.136, 2002.

BRASIL. Lei o 9.985, de 18 de julho de 2000. Cria o Sistema nacional de Unidades de Conservação da Natureza e dá outras providências. Disponível em: <http://www.planalto.gov.br/ccivil 03/leis/L9985.htm>. BRASIL. Ministério do Meio Ambiente. Portaria no 350, de 11 de dezembro de 2006. Brasília, DF, 2006. Acesso em 16 jun 2021.

BOCUHY, C. A inaceitável extinção de institutos de pesquisa ambiental em SP. O Eco (2021). Disponível em: <https://www.oeco.org.br/colunas/a-inaceitavelextincao-de-institutos-de-pesquisa-ambiental-em-sp/> 2021. Acesso em 08 jul 2021.

ESQUINSANI, R. S. S. Rupturas e continuidades no processo de transição administrativa. Revista Espaço Acadêmico, № 97, junho de 2009.

FERNANDES, M.E.S.A. O World Café e o aprendizado pelo diálogo: Limites e possibilidades de um território de sentidos no processo de formação "Diagnóstico Social ambiental na APA Embu Verde: Educação Ambiental para a sustentabilidade na bacia do rio cotia" Embu das Artes ,SP. tipo (Tese) São Paulo,2015.

GELDMANN, J. et al. Changes in protected area management effectiveness over time: A global analysis. Biological Conservation, v.191 p.692-699, 2015

IUCN (América do Sul - Escritório Regional). Relatório Anual - 2019. Disponível em: < https://portals.iucn.org/library/sites/library/files/documents/2020012-Pt.pdf>, Acesso em: 09 set 2021.

LEONEL, C. et al. A contribuição dos planos de manejo na conservação biológica: a experiência do núcleo planos de manejo da fundação florestal do estado de São Paulo. In: FIGEROA, E. B. (ed.), Conservación de la Biodiversidad en las Américas: Lecciones y Recomendaciones de Política, p. 499-534. Programa Domeyko en Biodiversidad de la Universidad de Chile, Secretaría del Medio ambiente del estado de Sao Paulo, Brasil. Editorial FENUniversidad de Chile, Santiago, Chile: 2011.

MARCONI, M. A.; LAKATOS, E. M. Fundamentos de Metodologia Científica. 5 ed. - São Paulo : Atlas 2003.

MEDEIROS, R.; PEREIRA, G,S. Evolução e Implementação dos Planos de Manejo em Parques Nacionais no Estado do Rio de Janeiro. Revista Árvore, Viçosa-MG, v.35, n.2, p.279-288, 2011.

MITLEWSKI, B. Avaliação do Projeto de Preservação da Mata Atlântica de São Paulo - PPMA (relatório). GOPA wordwide Consultants. p.111, 2006.

MITTERMEIER, R. A. et al. Hotspots revisited: earth's biologically richest and most endangered terrestrial ecoregions. Local: CEMEX, 2005. Disponível em:

$<$ https://www.researchgate.net/publication/275651117 Hotspots Revisited Earth 's Biologically Richest and Most Endangered Terrestrial Ecoregions> Acesso em: 10 set 2021.

NEWING, $\mathrm{H}$ et al. Conducting Research in Conservation - A Social perspective. p.325. Routledge. London and New York: 2011. 
NOGUEIRA, F. A. Continuidade e Descontinuidade Administrativa em Governos Locais: Fatores que sustentam a ação pública ao longo dos anos. Fundação Getúlio Vargas. Escola de Administração de Empresas de São Paulo. Dissertação de Mestrado. São Paulo: 2006.

PRATES, A, P, L.; IRVING, M, A. Conservação da biodiversidade e políticas públicas para as áreas protegidas no Brasil: desafios e tendências da origem da CDB às metas de Aichi. Revista Brasileira de Políticas Públicas. Vol. 5. № 1. Brasília: 2015.

REIS, A, F. Análise do Processo de Elaboração do Plano de Manejo do Parque Estadual do Jaraguá-SP. Monografia. CEGEA. São Paulo: 2011.

SAYRE, R et al. Naturezaem Foco: Avaliação Ecológica Rápida. The Nature Conservancy, Arlington, Virginia, USA.p.182, 2000.

SÃO PAULO (Estado). Planos de Manejo das Unidades de Conservação: Estação Ecológica de Bananal - Fase 1 - Plano de Gestão Ambiental. Série: Projeto de Preservação da Mata Atlântica. Secretaria do Meio Ambiente/ Coordenadoria de Informações Técnicas, Documentação e Pesquisa Ambiental, Instituto Florestal, Fundação Florestal. SMA: 1998.

SÃO PAULO (Estado). Secretaria de Meio Ambiente: Instituto Florestal. Portaria Diretor Geral de 30/12/98. Designa os membros para compor o Comitê de Apoio a Gestão da Estação Ecológica de Bananal. São Paulo: 1998.

SÃO PAULO (Estado). Secretaria de Meio Ambiente. Projeto de Preservação da Mata Atlântica: São Paulo: SMA.p.72, 2006.

SÃO PAULO (Estado). Secretaria de Meio Ambiente (Fundação Florestal). Termo de Referência para elaboração do Plano de Manejo da Estação Ecológica de Bananal. São Paulo: 2011.

SÃO PAULO (Estado). Secretaria de Meio Ambiente (Fundação Florestal). Relatório do Módulo Ocupação Antrópica do Plano de Manejo da Estação Ecológica de Bananal (em elaboração). São Paulo: 2011.

SÃO PAULO (Estado). Secretaria de Meio Ambiente (Fundação Florestal) Plano de Manejo da Estação Ecológica de Bananal (em análise no CONSEMA), $2021 . \quad$ Disponível em: $<$ https://www.sigam.ambiente.sp.gov.br/sigam3/Repositorio/511/Documentos/EE BANANAL/TEMPLETE EE\%20Bananal 18julho2019.pdf>. Acesso em: 17 jun 2021.

SÃO PAULO (Estado). Decreto no 60.302, de 27 de março de 2014. Institui o Sistema de Informação e Gestão de Áreas Protegidas e de Interesse Ambiental do Estado de São Paulo - SIGAP e dá providências correlatas. São Paulo, 2014

SANTOS, R.F. Princípios de Planejamento Ambiental. Livre docência. Universidade Estadual de Campinas. Faculdade de Engenharia Civil. p.215. Campinas: 2003.

SPINK, P. Continuidade e descontinuidade em organizações públicas: um paradoxo democrático. Cadernos FUNDAP - ano 7 - n`13. P. 57 - 65. São Paulo: 1987. 
TEIXEIRA, J,P,F. APqC contesta na justiça a extinção de institutos da área ambiental em SP. Blog APqC. São Paulo: 2021. Disponivém em: $<$ https://portal.apqc.org.br/5525-2/>. Acesso em: 15 out 2021.

THAPA, B. Managing Protected Areas: Global Perspectives Introduction to the Special Issue. Journal of Park and Recreation Administration. Volume 31, Number 2 pp. 1-5. 2013.

Alessandra Freire dos Reis: ESALQ/CENA-USP, Piracicaba, SP, Brasil

E-mail: freire.le@gmail.com

Link para o curriculum lattes: http://lattes.cnpq.br/7759087059213016

Maria Inez Pagani: Universidade Estadual Paulista Júlio de Mesquita Filho, Rio Claro, SP

E-mail: mipagani@gmail.com

Link para o curriculum lattes: http://lattes.cnpq.br/7524778123773562 